\title{
A kinetic and kinematic analysis of the Harai-goshi judo technique
}

\author{
J. M. Pucsok, K. Nelson, E. D. Ng \\ Physical Education Department, Slippery Rock University, Slippery Rock, Pennsylvania, United States
}

Received: January 17, 2002

Accepted: March 25, 2002

The purpose of this study was to analyze and compare the kinetic and kinematic characteristics of the throwing technique, Harai-goshi of novice and advanced judo competitors.

A heterogeneous group of 28 male and female judo competitors participated in this study. Each subject was required to perform three successful trials. Kinetic and kinematic data were collected by utilizing the Kistler Instrument Corporation Multicomponent Force Measuring Platform System and the Peak Technologies Motion Video Analysis System. Data were collected in order to quantitatively and qualitatively analyze the horizontal and vertical forces of the support leg, and the horizontal and vertical velocities of the sweeping leg during execution of the throwing technique, Harai-goshi (hip sweep). The study revealed a significant difference in horizontal force application, between novice and advanced judo competitors. In addition, we found numerous significant relationships among mean horizontal ground reaction force application and horizontal leg sweep velocity in 19 of the 28 participants when analyzed individually.

The results suggest (1) leg sweep velocity is a function of ground reaction force application; and (2) horizontal leg sweep velocity plays a primary role in good technical execution of the Harai-goshi throw.

Keywords: Harai-goshi judo, throwing technique

The sport of judo does not involve punching or kicking, but rather is a refined version of the ancient martial arts of ju-jitsu and kito-ryu (20). Judo incorporates the use of throwing techniques, mat work similar to modern wrestling, and strangulation holds and joint locks at the elbow. Such sports as judo are typically labeled "technical" sports and, as such, lend themselves particularly well to biomechanical study (30). As a sport, judo incorporates an assortment of grappling skills that follow basic natural rules. There are five main factors, based on the laws of physics which notably influence judo

Correspondence should be addressed to

J. M. Pucsok

H-1025 Budapest, Tömörkény utca 10/a, Hungary

Phone: 06/20-9-44-66-72

E-mail: pucsokjozsi@freemail.hu 
performance: the base of support, the center of gravity, the line of gravity, the concept of levers, and the laws of motion. Judo is a sport in which timing, stability, body anthropometry, equilibrium, leverage, inertia, and acceleration are critical to performance. Proper execution of movements is not only important to success, but also may reduce possible injury sustained by the judo competitor.

Despite its rich heritage and history there have been only a few studies to date which have analyzed the kinetic and kinematic characteristics of judo techniques in this sport. The early scientific studies were primarily kinetic analyses, which stated how the laws of physics play a role in the sport of judo.

\section{Methods and Procedures}

\section{Selection of subjects}

A heterogeneous group of 28 judo competitors males and females, ages 18-42, with various body weight and height were selected for this investigation. Each subject (tori) was randomly assigned to perform the technique, Harai-goshi to the right side dressed in judogi (judo uniform) and in bare feet. Each subject was required to perform three successful trials. Subject skill level was determined according to the japanese judo grade system, using kyu or dan ranks, indicated by the wearing of different color belts. Seventeen judo competitors represented the novice level (Group 1) and 11 judo competitors the advanced level (Group 2). Bodyweight differences were treated statistically as presented later in this article. One individual was selected by the investigator to serve as the uke throughout the entire test procedure in order to minimize subject variability during the throw.

\section{Procedures for aquiring data}

Data were collected in order to quantitatively and qualitatively analyze the horizontal and vertical forces of the support leg, and the horizontal and vertical velocity of the sweeping leg during execution of the throwing technique, Harai-goshi. The horizontal and vertical forces and the horizontal and vertical velocity were measured in kilograms and in meters/second, respectively. Force versus time graphs and plotter images were superimposed over one another in order to identify trends (Fig. 1).

Before the actual administration of the test, the investigator provided an opportunity for the subjects to familiarize themselves with the test environment. 


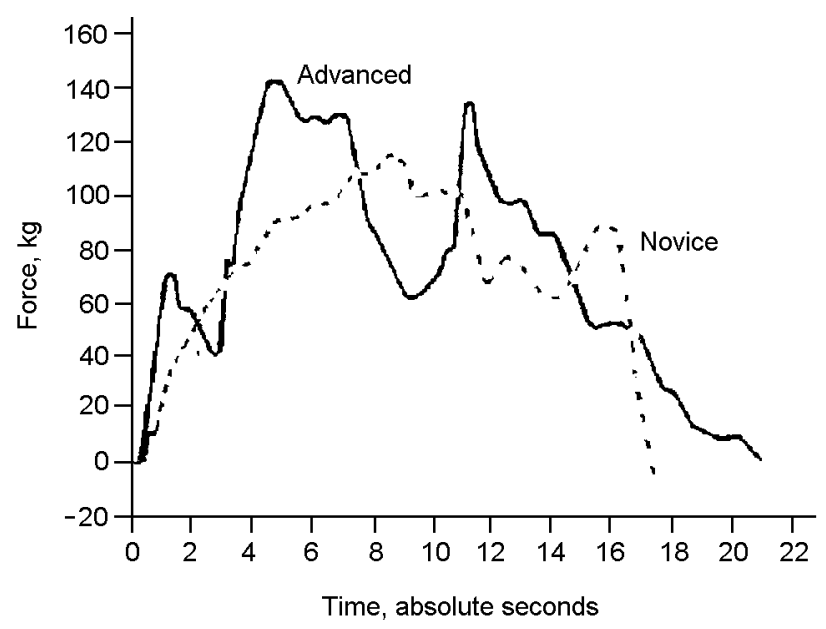

Fig. 1. Force versus time graph of trial \# 2 of subjects (5) and (18)

Each subject was randomly assigned to perform the technique, Harai-goshi to the right side dressed in judogi and in bare feet. The uke and the tori started the test by facing one another while standing off the force platform and grasping each other's judogi in the right natural grip. Tori initiated the technique by stepping onto the force platform with the right foot. This was followed by a step with the left foot and the sweeping action of the right foot and leg. Uke was lifted off the ground thrown by the tori, and landed on the mats surrounding the test site. Each subject was required to perform three successful trials. A trial was determined successful when the force platform system accepted the data without an error message displayed on the monitor. At the same time, the subject's throwing trials were recorded on VHS professional quality tape using a Panasonic SVHS AG450 Camcorder video camera. First the camera was positioned with its optical axis to the subject's sagittal plane and toe line. The camera lens were positioned approximately $500 \mathrm{~cm}$ from the subjects. The lens height was approximately $110 \mathrm{~cm}$ from the floor. Filming a $182 \mathrm{~cm}$ measuring rod marked in $30.48 \mathrm{~cm}$ segments provided a scaling factor. The rod was held vertical at the toe line adjacent to the subjects (29).

Kinematic data analysis began with encoding the frames of the throwing trials. After encoding the videotape, the throwing trials were digitized frame by frame. The Peak5 2D software and video hardware was used to digitize the sequences by the RAM memory frame grabber board, which stored the digitized $512 \times 512$ pixel pictures. The successful trials recorded by the video camera were analyzed for each subject. As for kinetic data collection, a successful trial was determined when the Kistler Instrument Corporation Multicomponent Force Measuring Platform accepted the data without an error message displayed on the monitor and if the throw was performed correctly. For 
the kinematic analysis all the frames of the selected trials were digitized and qualitatively accessed using a Panasonic SVHS AG7350 VCR videocassette recorder (29).

\section{Treatment of the data}

The kinetic and kinematic analysis of the selected judo technique necessitated the use of two different statistical designs. The Pearson Product Moment Correlation and the Analysis of Covariance (ANCOVA) tests were selected as the appropriate statistics in order to test relationships and to compare the kinetic and kinematic differences between the groups, respectively. Accepting the assumption that force application and leg sweep velocity will be influenced by differences in bodyweight, and if the body weights are statistically different between the novice and advanced groups, the analysis for hypotheses 3-6 incorporated statistical control of the covariant (bodyweight).

Two hypotheses were analyzed by the Pearson Product Moment Correlation test to establish significance of relationships of the following: (1) The vertical ground reaction forces and vertical sweep leg velocities, and (2) The horizontal ground reaction forces and horizontal sweep leg velocities. For each individual, force and velocity data per 0.05 seconds were plotted. The correlation analysis was performed on anywhere between 57 and 104 pairs of force/velocity data. Correlation coefficients were determined for each of the 28 subjects. These were tested in the null form at the 0.05 level of significance $(\mathrm{p}<0.05)$. If the novice and advanced subject's body weights are statistically different, then three hypotheses were analyzed by the Analysis of Covariance (ANCOVA) test to establish significance of differences of the following: (3) The vertical ground reaction force application between novice and advanced judo competitors, (4) The horizontal ground reaction force application between novice and advanced judo competitors, (5) The vertical sweep leg velocity between novice and advanced judo competitors, and (6) The horizontal sweep leg velocity between novice and advanced judo competitors. If the body weights were statistically similar, then the Independent $t$-test were used to analyze data. These were also be tested in the null form at the 0.05 level of significance $(\mathrm{p}<0.05)$. Force versus time graphs and plotter images were superimposed over one another in order to identify trends.

\section{Results and Discussion}

Hypothesis (1) stated that there would be no significant relationship between mean vertical ground reaction force application and vertical leg sweep velocity within trials of individual judo competitors. Kinetic and kinematic data of 10 out of 17 novice 
subjects indicated no significant relationship $(\mathrm{p}<0.05)$ between mean vertical ground reaction force application and vertical leg sweep velocity. Seven out of 17 novice subjects demonstrated significant relationship between mean vertical ground reaction force application and vertical leg sweep velocity. Kinetic and kinematic data of 7 out of 11 advanced subjects indicated no significant relationship $(\mathrm{p}<0.05)$ between mean vertical ground reaction force application and vertical leg sweep velocity. Four out of 11 advanced subjects demonstrated a significant relationship $(\mathrm{p}<0.05)$ between mean vertical ground reaction force application and vertical leg sweep velocity. Overall, in 17 out of 28 cases, there was no significant relationship between mean vertical ground reaction force application and vertical leg sweep velocity (Table I).

Hypothesis (2) stated that there would be no significant relationship between mean horizontal ground reaction force application and horizontal leg sweep velocity. Kinetic and kinematic data of 5 out of 17 novice subjects indicated no significant relationship $(p<0.05)$ between mean horizontal ground reaction force application and horizontal leg sweep velocity. Twelve out of 17 novice subjects demonstrated significant relationship $(\mathrm{p}<0.05)$ between mean horizontal ground reaction force application and horizontal leg sweep velocity. Kinetic and kinematic data of 4 out of 11 advanced subjects indicated no significant difference $(\mathrm{p}<0.05)$ between mean horizontal ground reaction force application and horizontal leg sweep velocity. Seven out of 11 advanced subjects demonstrated significant relationship $(\mathrm{p}<0.05)$ between mean horizontal ground reaction force application and horizontal leg sweep velocity. Overall, in 19 out of 28 cases, there was a significant relationship between mean horizontal ground reaction force application and horizontal leg sweep velocity (Table II). The degrees of freedom values for individual analysis within hypotheses (1) and (2) are displayed in a table format (Table III).

Hypothesis (3) stated that there would be no significant difference in mean vertical ground reaction force application, between novice and advanced judo competitors found no significant difference $(t=1.06, p>0.05)$ between subjects representing novice and advanced skill levels in mean vertical ground reaction force application.

Hypothesis (4) stated that there would be no significant difference in mean horizontal ground reaction force application, between novice and advanced judo competitors. There was a significant difference $(\mathrm{t}=1.73, \mathrm{p}<0.05)$ between novice and advanced judo competitors in mean horizontal ground reaction force application.

Hypothesis (5) stated that there would be no significant difference in vertical leg sweep velocity, between novice and advanced judo competitors. The investigator found no significant difference $(\mathrm{t}=0.57, \mathrm{p}>0.05)$ between novice and advanced judo competitors in vertical leg sweep velocity. 
Table I

Mean vertical ground reaction force $r$ values for each subject according to skill level

\begin{tabular}{cccc}
\hline Novice group & r value & Advanced group & r value \\
\hline Subject 1 & 0.20 & Subject 2 & 0.12 \\
Subject 3 & $-0.26^{*}$ & Subject 9 & $-0.54^{*}$ \\
Subject 4 & -0.20 & Subject 11 & -0.15 \\
Subject 5 & $-0.27^{*}$ & Subject 13 & $-0.21^{*}$ \\
Subject 6 & -0.01 & Subject 14 & 0.12 \\
Subject 7 & 0.12 & Subject 16 & -0.09 \\
Subject 8 & $-0.31^{*}$ & Subject 17 & $-0.66^{*}$ \\
Subject 10 & $-0.44^{*}$ & Subject 18 & -0.22 \\
Subject 12 & $-0.56^{*}$ & Subject 21 & 0.06 \\
Subject 15 & 0.11 & Subject 22 & -14 \\
Subject 19 & -0.17 & Subject 24 & \\
Subject 20 & -0.04 & & \\
Subject 23 & 0.13 & & \\
Subject 25 & -0.21 & & \\
Subject 26 & -0.03 & & \\
Subject 27 & $-0.40^{*}$ & & \\
Subject 28 & $-0.25^{*}$ & & \\
\hline
\end{tabular}

$* \mathrm{p}<0.05$

Table II

Mean horizontal ground reaction force $r$ values for each subject according to skill level

\begin{tabular}{|c|c|c|c|}
\hline Novice group & r value & Advanced group & r value \\
\hline Subject 1 & 0.02 & Subject 2 & 0.00 \\
\hline Subject 3 & -0.05 & Subject 9 & $-0.44 *$ \\
\hline Subject 4 & $-0.52 *$ & Subject 11 & $-0.52 *$ \\
\hline Subject 5 & -0.13 & Subject 13 & -0.20 \\
\hline Subject 6 & $-0.25^{*}$ & Subject 14 & $-0.46^{*}$ \\
\hline Subject 7 & $-0.46^{*}$ & Subject 16 & $-0.41 *$ \\
\hline Subject 8 & $-0.47^{*}$ & Subject 17 & $-0.58 *$ \\
\hline Subject 10 & $-0.27 *$ & Subject 18 & $-0.38 *$ \\
\hline Subject 12 & -0.14 & Subject 21 & $-0.26^{*}$ \\
\hline Subject 15 & -0.03 & Subject 22 & -0.10 \\
\hline Subject 19 & $-0.35^{*}$ & Subject 24 & -0.23 \\
\hline Subject 20 & $-0.29 *$ & & \\
\hline Subject 23 & $-0.33^{*}$ & & \\
\hline Subject 25 & $-0.30^{*}$ & & \\
\hline Subject 26 & $-0.43^{*}$ & & \\
\hline Subject 27 & $-0.31 *$ & & \\
\hline Subject 28 & $-0.60^{*}$ & & \\
\hline
\end{tabular}

$* \mathrm{p}<0.05$ 
Table III

Degrees of freedom values for each subject

\begin{tabular}{lclc}
\hline Novice group & df(n-2) & Advanced group & df(n-2) \\
\hline Subject 1 & 67 & Subject 2 & 81 \\
Subject 3 & 75 & Subject 9 & 92 \\
Subject 4 & 78 & Subject 11 & 70 \\
Subject 5 & 91 & Subject 13 & 78 \\
Subject 6 & 77 & Subject 14 & 55 \\
Subject 7 & 77 & Subject 16 & 65 \\
Subject 8 & 86 & Subject 17 & 67 \\
Subject 10 & 82 & Subject 18 & 71 \\
Subject 12 & 102 & Subject 21 & 72 \\
Subject 15 & 98 & Subject 22 & 62 \\
Subject 19 & 68 & Subject 24 & \\
Subject 20 & 81 & & \\
Subject 23 & 73 & & \\
Subject 25 & 72 & & \\
Subject 26 & 72 & & \\
Subject 27 & 71 & & \\
Subject 28 & 72 & & \\
\hline
\end{tabular}

For hypothesis (6) the investigator found no significant difference $(t=1.41$, $\mathrm{p}>0.05$ ) between novice and advanced judo competitors in horizontal leg sweep velocity.

\section{Conclusions}

Within the limitations of this study the following conclusions appear warranted: For hypothesis (1), based on a significance level of 0.05 no significant relationship was found for the following subjects: 1, 2, 4, 6, 7, 11, 14, 15, 16, 18, 19, 20, 21, 22, 23, 25, 26. For hypothesis (2) based on a significance level of 0.05 significant relationship was found for the following subjects: 4, 6, 7, 8, 9, 10, 11, 14, 16, 17, 18, 19, 20, 21, 23, 25, $26,27,28$. Based on a significance level of 0.05 null hypotheses (3), (5) and (6) were accepted, null hypothesis (4) was rejected.

The results indicated that there was a significant relationship between the horizontal ground reaction force application and horizontal leg sweep velocity for 17 individual judo competitors, during the performance of the Harai-goshi throwing technique. 
We found a statistically significant difference in horizontal ground reaction force application, between competitors of novice judo experience and competitors of advanced judo experience, during the performance of the Harai-goshi throwing technique. Both findings suggest the extreme importance of the horizontal component in the execution of the Harai-goshi technique.

\section{Definitions of terms}

The following terms have been defined within the context of this study:

Advanced. Operationally defined as a judo competitor possessing a 2nd, 1st kyu or dan ranks indicated by the color of his or her belt.

Base of support. "The area bound by the outermost regions of contact between a body and support surface or surfaces" (16, p. 379).

Center of gravity. "The point from which the body must be suspended in order to remain in static equilibrium in any position in which it is placed" (13, p. 216).

Dan. The level of expertise or grade of rank indicated by the black belt in judo (12, 1991).

Harai-goshi. Hip sweep, a throwing technique executed by the participants of judo $(20,1986)$.

Judogi. The judo uniform worn by individuals participating in the sport $(20,1986)$.

$J u$-jitsu. "Science of softness" techniques of combat developed in the Kamakura period (1185-1333 AD) in Japan (12, p. 86).

Kinematics. The description of movement, including velocity and acceleration of the whole body and its segments (18).

Kinetics. The description of movement, which considers the forces that produce or change motion (22).

Kito-ryu. An ancient school of ju-jitsu which developed from the 17th to the 18th century in Japan (12).

$K y u$. The level of expertise or grade of rank in judo (20).

Line of gravity. Vertical line connecting the point of center of gravity with the base of support (16).

Novice. Operationally defined as a judo player who is in the early stages of judo training possessing a 6th, 5th, 4th or 3rd kyu rank, indicated by belt.

Support leg. Operationally defined as the tori's left leg when performing the Haraigoshi throw.

Sweep leg. Operationally defined as the tori's right leg when performing the Haraigoshi throw.

Tori. The individual who is performing a technique (20).

Uke. The individual who is being manipulated or thrown (20). 


\section{REFERENCES}

1. Alexander MJL: Gender differences in biomechanical aspects of performance. Critical Reviews in Physical and Rehabilitation Medicine, 10, 15-36 (1998)

2. Ashida S: Current trends in judo techniques. Paper presented at the United States Judo Federation National Coaches Conference, Colorado Springs, CO (1995)

3. Beiser A (1986): Physics (4th ed.). Menlo Park, CA: Benjamin Cummings

4. Berkow R, Beers MH, Fletcher AJ: The Merck manual of medical information: Home edition. Whitehouse Station, NJ: Merck \& Co (1997)

5. Blanchard RG: The mechanics of judo: analytical studies of selected standing techniques. Rutland, VT: Charles E Tuttle (1961)

6. Cooper JM, Adrian M, Glassow RB: Kinesiology. (5th ed.). St. Louis, MO: Mosby (1982)

7. Cunningham SR: A brief look at the "Root Arts" of judo. Retrieved September 15, 1999 from Netscape, World Wide Web:.sp.uconn.edu/ roots.htm (1996)

8. Cunningham SR: Judo: Morality and the physical art. Paper presented at the United States Judo Federation National Coaches Conference, Colorado Springs, CO (1998)

9. Daigo T: Osotogari, judo. Kodokan, 65, 34-39 (1994)

10. De Meersman RE, Wilkerson JE.: Judo nephropathy: Trauma versus non-trauma. The Journal of Trauma, 22, 150-152 (1982)

11. Exton M, Iura Y: A biomechanical study on tomoe-nage of judo techniques. The Study of Martial Arts, 23, 24-34 (1991)

12. Frederic L: A dictionary of the martial arts. Rutland, VT: Charles E Tuttle (1991)

13. Freeman IM: Physics: Principles and insights. New York: McGraw-Hill (1968)

14. Fukuda K: Born for the mat; a Kodokan kata textbook for women, judo. (2nd ed.). San Francisco: Author (1974)

15. Haga S, Ueya K: Techniques of nage-waza of judo biomechanical study. United States Judo Federation News, 10, 21-26 (1996)

16. Hall S: Basic biomechanics. St. Louis, MO: Mosby (1991)

17. Harter RA, Bates BT: Kinematic and temporal characteristics of selected judo hip throws. In Terauds, J. and Barham, J. N. (Eds.), Proceedings of the International Society of Biomechanics in Sports 1985 Symposium (pp. 141-150). Del Mar, CA: Academic Publishers (1985)

18. Hay JG: The biomechanics of sports techniques. (3rd ed.). Englewood Cliffs, NJ: Prentice-Hall (1985)

19. Hellebrandt FA, Riddle KS, Larsen EM, Fries EC: Gravitational influences on postural alignment. Physiotherapy Review, 22, 143-149 (1942)

20. Kano J: Kodokan judo. New York: Kodansha International (1986)

21. Lafon G: Coaching corner: Are you training efficiently? Retrieved September 2, 1999 from Netscape, World Wide Web: judoamerica.com/coaches/training.shtml (1997)

22. Luttgens K, Hamilton N: Kinesiology: Scientific bases of human motion. (9th ed.). Dubuque, IA: Brown \& Benchmark (1997)

23. Luttgens K, Wells KF: Kinesiology: Scientific bases of human motion. (7th ed.). Philadelphia: Saunders College Publishing (1982)

24. Miura S: An electrogoniometric study of a judo throwing technique (Uchi-mata, inner thigh reaping). Judo, 4, 51-59 (1970)

25. Miura S, Takeuchi H: A study of effects of the neck joint on the skill of judo. United States Judo Federation News, 6, 17-25 (1996)

26. Maekawa M, Hasegawa Y: Studies on Jigoro Kano: Significance of his ideals of physical education and judo. Bulletin for the Association for the Scientific Studies on Judo (Report No. 2, pp. 1-12). Tokyo: Kodokan Judo Institute (1963)

27. Michigan Women's Weightlifting \& Judo: Introduction to the principles of judo. Retrieved September 5, 1999 from Netscape, World Wide Web: jptimes.com/judo 1.htm (1999) 
28. Nakabayashi S, Uchida Y, Uchida G: Fundamentals of judo. New York: Ronald Press (1964)

29. Ng N: Kinesiology/biomechanics lab manual. (6th ed.). Slippery Rock, PA: Slippery Rock University (1991)

30. Nishioka H: Physics of judo. Black Belt, 6, 26-30 (1968)

31. Palmer CE.: Studies of the center of gravity in the human body. Child Development, 15, 99-180 (1944)

32. Rasch PJ: Kinesiology and applied anatomy. (7th ed.). Philadelphia: Lea \& Febiger (1989)

33. Takhashi K: An electromyographic study of a judo throwing technique (Osoto-gari-major outer reaping). Judo, 42, 55-61 (1971)

34. Tezuka M, Funk S, Purcell M, Adrian M: Kinetic analysis of judo technique. In Matsui, H. \& Kobayashi, K. (Eds.), Biomechanics, VIII-B (pp. 869-875). Champaign, IL: Human Kinetics (1983)

35. Todo Y, Murata N: A study on the origin of the name of judo. Bulletin for the Association for the Scientific Studies on Judo (Report No. 8). Tokyo: Kodokan Judo Institute (1999)

36. Tomiki K: Judo. Japan Travel Bureau (1956)

37. Walker J: The physics of judo and aikido. Scientific American, 243, 150-161 (1980)

38. Watanabe J, Avakian L: The secrets of judo: A text for instructors and students. Rutland, VT: Charles E Tuttle (1990)

39. Yiannakis A, Cunningham S: Ju-jutsu and the origins of judo: A brief history. Retrieved August 25, 1999 from Netscape, World Wide Web: (1995) 